\title{
Relaxation of residual stresses in brush-plated gold and silver coatings on copper and on brass substrates
}

\author{
Harri Lille ${ }^{1, a^{*}}$, Jakub Kõo ${ }^{1, b}$, Alexander Ryabchikov ${ }^{1, c}$, Renno Reitsnik ${ }^{1, d}$, \\ Fjodor Sergejev ${ }^{2, e}$ and Minjie Dong ${ }^{3, f}$ \\ ${ }^{1}$ Institute of Forestry and Rural Engineering, Estonian University of Life Sciences, \\ Kreutzwaldi 5, 51014 Tartu, Estonia \\ ${ }^{2}$ Department of Materials Engineering, Tallinn University of Technology, \\ Ehitajate tee 5, 19086 Tallinn, Estonia \\ ${ }^{3}$ Centre for Materials Research, Tallinn University of Technology, Estonia \\ Ehitajate tee 5, 19086 Tallinn, Estonia \\ aharri.lille@emu.ee, bjakub.koo@emu.ee, calexander.ryabchikov@emu.ee, \\ drenno.reitsnik@emu.ee, ${ }^{\mathrm{e}}$ fjodor.sergejev@ttu.ee, ${ }^{f}$ minjie.dong@ttu.ee
}

Keywords: brush-plated coatings, residual stress relaxation, curvature method, indentation technique, morphology, microstructure

\begin{abstract}
The investigated brush-plated gold and silver coatings are used for refining the surface properties of electric apparatuses. Tensile residual stresses generated in the plated coatings were determined by the curvature method and by instrumented indentation testing of a thin-walled open ring substrate, as described in our earlier papers. These stresses relax over time and their dependence on relaxation time was approximated by a linear-fractional function. The Young's modulus and nanohardness of the coatings were determined. The surface morphology and structure in cross section of the coated substrates were presented.
\end{abstract}

\section{Introduction}

Hard gold and silver coatings have met application in engineering use (e.g. on generators slip rings, sliding contacts and small machine parts) due to their high hardness and wear resistance as well as their effective protection. They are typically plated on copper (mostly), brass and bronze. Silver is often used as low-price replacement for gold.

Brush-plating is a simple processing method for selective plating of desired materials onto metallic materials without dipping the machine part (work piece) into a tank of the electrolyte. As the plating process takes place at room temperature, no heater is required. Usually, alloying metals or nanoparticle composites are added to pure gold and silver. Nickel-hardened gold and silver coatings were brush-plated from an industrial SIFCO Dalic Solution (Gold Hard Alloy) pH 8.4, Code SPS 5370, and Silver Hard Heavy Build pH 11.7, Code SPS 3083, on thin-walled open copper and brass ring substrates of various thickness [1,2,3]. In the present paper residual stresses in the plated coatings were determined by the curvature method and by an instrumented indentation testing technique. Relaxation of residual stresses was observed over a long time and some properties of the coatings, e.g. modulus of elasticity and nanohardness, which affect the service life of electrical components, were determined.

\section{Residual stresses in the coatings and experimental methods}

In electrodeposition there arise residual stresses whose origin is described in literature [4]. Residual stresses in the coatings were calculated from the curvature changes of thin-walled open ring substrates. The equation is based on Brenner and Senderoff's concept according to which the substrate is considered a beam with slipping ends. The equation was modified to account for biaxial stresses as well as for the ring substrate with a shell shape which was additionally taken into consideration by a coefficient and was described in our earlier papers $[1,2,3]$. 


$$
\sigma=\frac{E_{1} b_{1} F}{12 \pi b_{2} R_{0}^{2}} \frac{\bar{f}_{4} \Delta \delta}{h_{1} h_{2}\left(h_{1}+h_{2}\right)}
$$

where $R_{0}$ is the middle radius of the substrate, $b_{1}$ and $b_{2}$ are the widths and $h_{1}$ and $h_{2}$ are the thicknesses of the substrate and coating, respectively, the coefficient

$$
F=\frac{1-\mu^{2} k}{\left(1-\mu^{2}\right)(1-\mu k)}, \quad \text { where } k=\frac{2}{\beta b^{*}} \frac{\cosh \beta b^{*}-\cos \beta b^{*}}{\sinh \beta b^{*}+\sin \beta b^{*}},
$$

the ratio k depends on $\beta=\sqrt[4]{\frac{3\left(1-\mu^{2}\right) \bar{f}_{1}^{2}}{R_{0}^{2} \bar{f}_{4}}}$ and reduced substrate thickness $b^{*}=\frac{f_{1} \bar{f}_{4}}{\bar{f}_{1} f_{4}} b_{1}$,

where $\quad \bar{f}_{1}=h_{1}+\bar{\gamma} h_{2}, \quad \bar{f}_{4}=h_{1}{ }^{4}+4 \bar{\gamma} h_{1}{ }^{3} h_{2}+6 \bar{\gamma} h_{1}{ }^{2} h_{2}^{2}+4 \bar{\gamma} h_{1} h_{2}^{3}+\bar{\gamma}^{2} h_{2}^{4}, \quad \bar{\gamma}=\frac{E_{2} b_{2}}{E_{1} b_{1}}, \quad f_{1}=h_{1}+\gamma h_{2}$,

$$
f_{4}=h_{1}^{4}+4 \gamma h_{1}^{3} h_{2}+6 \gamma h_{1}{ }^{2} h_{2}^{2}+4 \gamma h_{1} h_{2}^{3}+\gamma^{2} h_{2}^{4}, \quad \gamma=\frac{E_{2}}{E_{1}} .
$$

$E_{1}, E_{2}$ are the moduli of elasticity of the substrate and coating, respectively. Poisson's ratio for the substrate and coating is assumed to be the same $\left(\mu_{1}=\mu_{2}=\mu\right), \Delta \delta$ is the measured slit increment.

Localized measurement of residual stresses in the coatings was evaluated by an instrumented indentation testing technique using a nanohardness apparatus $[5,6,7,8]$.

The effect of residual stress on the shape of the indentation curve has been addressed in [5-7]. The magnitude and the nature of residual stress affect the shape of the load-penetration or $P$ - $h$ curve (see Fig. 1) obtained by the instrumented indentation technique. Intensive intrinsic compressive residual stress increases the hardness of indented materials and shifts the indentation curve to the left, identifying lower indentation depth. High tensile residual stress, on the contrary, leads to lower hardness and higher indentation depth.

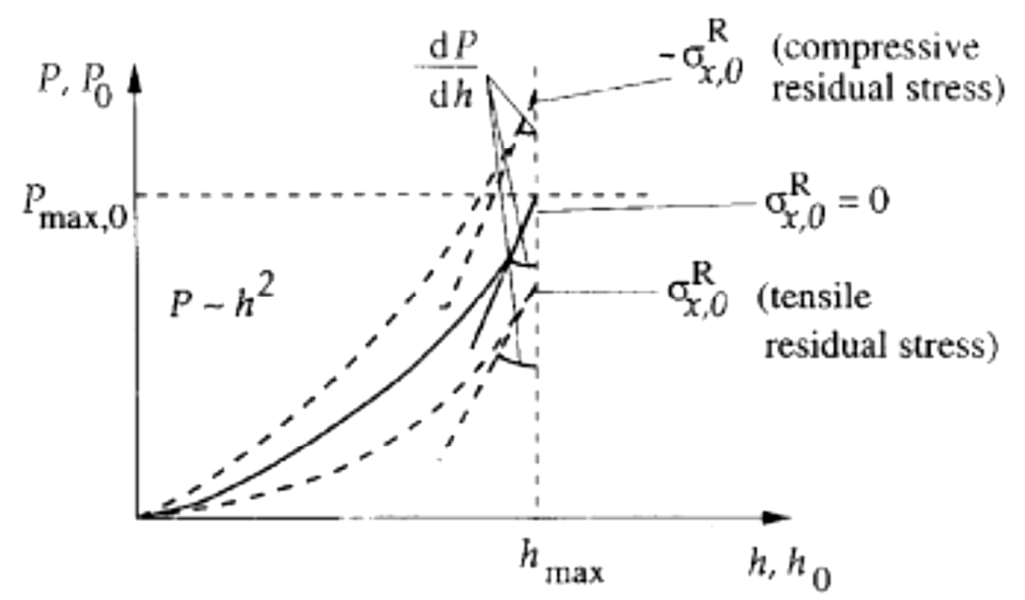

Fig. 1. Scheme of indentation load-penetration depth curves for surfaces with and without residual stress [5].

Biaxial tensile intrinsic residual stresses were calculated according to the model of Suresh and Giannakopoulos [8] as follows:

$$
\frac{A_{c}}{A_{0}}=\left(1-\frac{\sigma_{r}}{H}\right)^{-1}
$$

where $\sigma_{\mathrm{r}}$ is residual stress; $H$ is indentation hardness; $A_{\mathrm{c}}$ is the apparent contact area for a stressed sample and $A_{0}$ is the apparent contact area for a stress-free sample of a three-sided pyramidal Berkovich indenter used in nanoindentation.

In the case of the studied materials, residual stresses shift the $P$ - $h$ curve to higher indentation depths, see Fig. 2.

This indicates the presence of tensile or positive biaxial residual stress in the studied materials. 


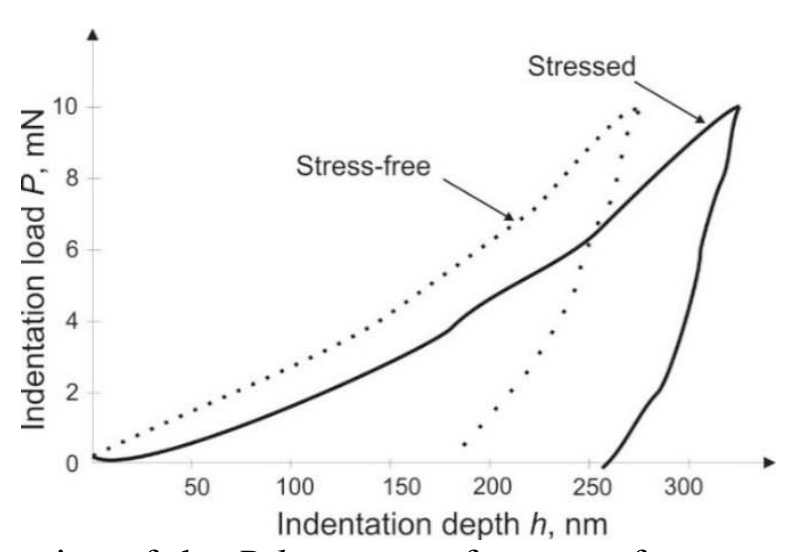

Fig. 2. Schematic representation of the $P$ - $h$ a curves for stress-free sample and for a sample under residual stress of the tested materials.

In the present case the magnitude of the modulus of elasticity and of nanohardness of the coatings were also obtained by means of instrumented indentation using a pendulum-type nanotester MTS Nano Indenter $X R^{\circledR}$. The Oliver-Pharr method was used to determine the reduced modulus and hardness from the load displacement curves, using a tip areas function [5,6]. Indentation was repeated at least 20 times for each material at three different loads $(3,5$ and $10 \mathrm{mN})$ and mean values were used.

These stresses relax over time; the dependence of relaxation time was approximated by the following linear-fractional function [1]

$$
\sigma(t)=\left(b\left(\sigma_{0}-\sigma_{f}\right) /(a t+b)\right)+\sigma_{f},
$$

where $\sigma_{0}$ is calculated residual (initial) stress of a freshly plated coating when $t=0, \sigma_{\mathrm{f}}$ is calculated finishing stress, $t$ is relaxation time (days), and $a$ and $b$ are constants. Constants should be determined so that calculated residual stresses are approximated in the best way by minimizing the square of error (least squares regression). This problem was solved by using the program Mathcad 15.0 with the regression function genfit (vx, vy, vg, F).

The surface morphology and the microstructure of the coatings were studied by means of scanning electron microscopy (SEM) using Zeiss EVO MA-15.

\section{Results and discussion}

The values of residual stresses were determined using a series of specimens (minimum of four specimens in one series) and mean values were employed. For the copper and brass ring substrates, the modulus of elasticity was $112 \mathrm{GPa}$ and $116 \mathrm{GPa}$, respectively, the Poisson's ratio was 0.34 , width was $\sim 11.0 \mathrm{~mm}$ and the middle radius was $15.32 \mathrm{~mm}$ and $15.42 \mathrm{~mm}$, depending on substrate thickness. The surface of the substrate before the coating procedure was polished to the mean roughness value $R_{\mathrm{a}}=0.081 \mu \mathrm{m}$ and the coating was plated at a cathode velocity of $0.39 \mathrm{~m} / \mathrm{sec}$. The width of the plated coatings was $\sim 10.5 \mathrm{~mm}$. The plating technology is described in [2,3] and the parameters are presented in Table 1.

The average characteristic indentation curves for the studied three gold and three silver coating materials are shown in Figs. 3 and 4. The position of the curves in the $P$ - $h$ graphs shows the decrease of the intrinsic residual tensile stress from material Au15C* to material Au15B*. The slope of the indentation curves indicates the similarity of the elastic moduli for the gold coating materials.

Previous indentation results [5] were used as a "stress-free" sample for calculation of biaxial tensile residual stress with appropriate approximation of the stress state. Determination of residual stress for the studied materials is complicated due to their high plasticity and the relatively thin layer of the deposited coating. Residual stresses determined by two techniques were in the same range 
within the maximum limit of experimental uncertainty. The calculated mean values of the residual stresses are presented in Table 1.

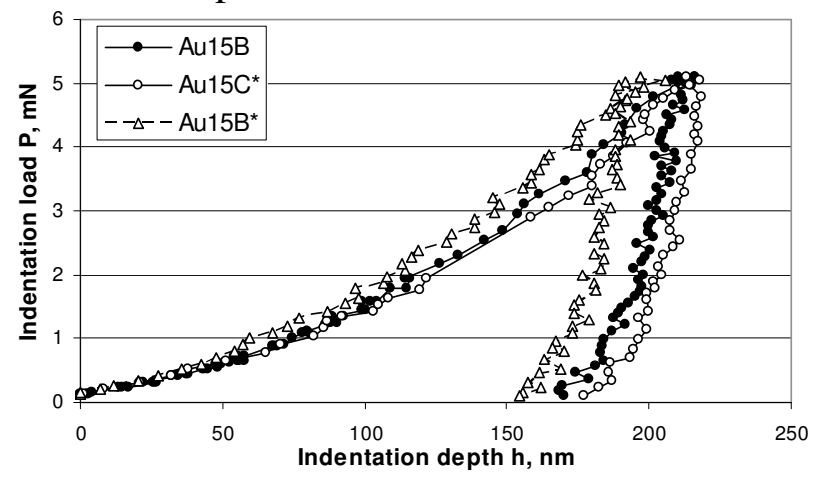

Fig. 3. Indentation curves for the studied gold coating materials at the indentation load $5 \mathrm{mN}$.

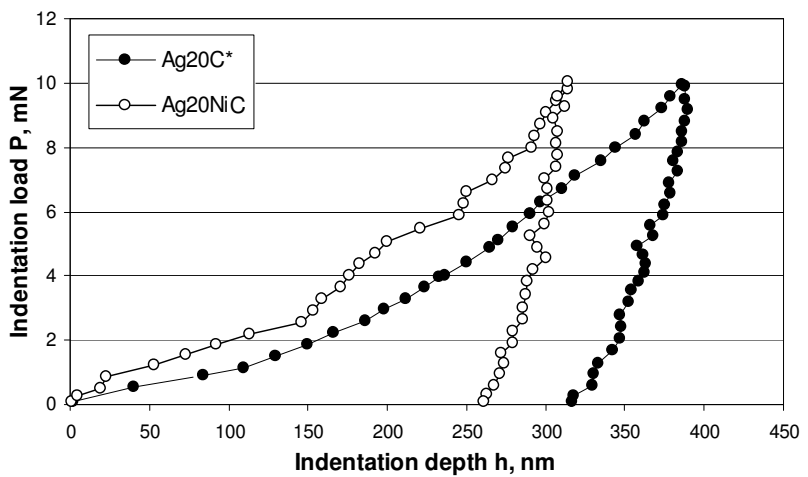

Fig. 4. Indentation curves for the studied silver coatings at the indentation load $5 \mathrm{mN}$.
The mean values of residual stresses $\sigma_{0}$ for freshly plated coatings and relaxed stresses $\sigma(\mathrm{t})$ for three cold coatings recorded for longer than seven years, for two silver coatings for longer than six months and for one silver coating for longer than three years, are presented in Figs. 5, 6 and in Table 1. The results showed that time affected residual stresses in the coatings to a great extent. In our experiments residual stresses did not depend significantly on the substrate or on coating thickness. Higher deposition temperature caused temperature stresses whose role in the residual stresses of gold and silver coatings is not significant due to low deposition temperature $\left(3-6^{\circ} \mathrm{C}\right.$ is the difference between depositing and measuring temperatures)

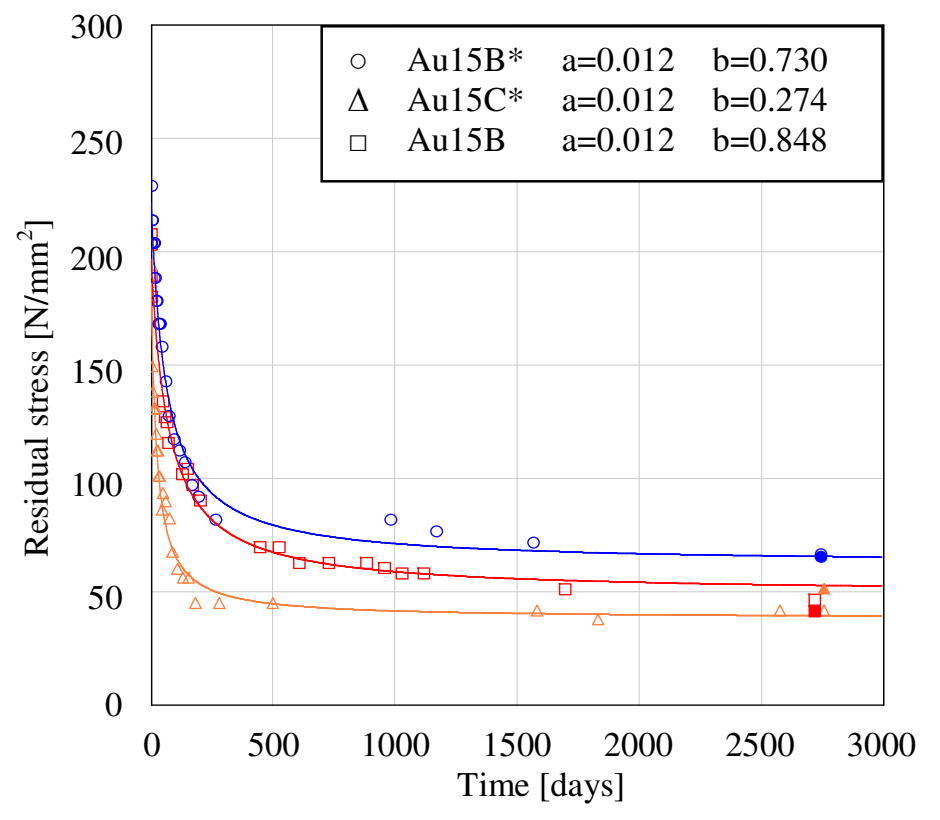

Fig. 5. Residual stresses in the gold coatings depending on relaxation time and the line of approximation; residual stresses (solid dots) determined by nanoindentation according to relaxation time.

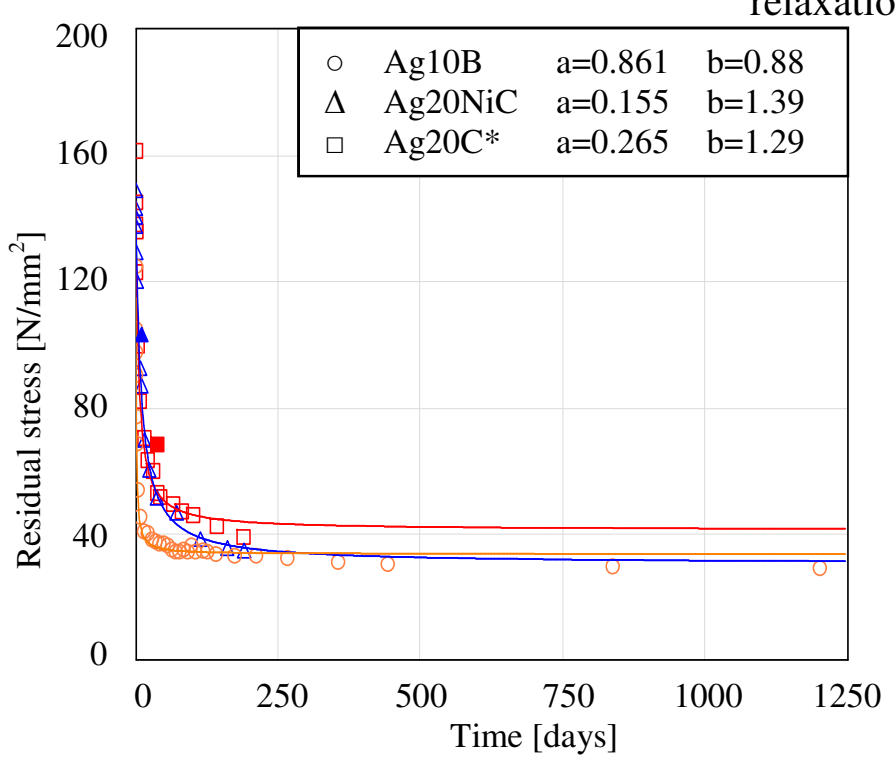

Fig. 6. Residual stresses in the silver coatings depending on relaxation time and the line of approximation; residual stresses (solid dots) determined by nanoindentation, according to relaxation time. 
Table 1. Coding of the coatings, brush plating parameters and coating properties

\begin{tabular}{|c|c|c|c|c|c|c|}
\hline Coating code & Au15B & $\mathrm{Au} 15 \mathrm{~B}^{*}$ & $\mathrm{Au} 15 \mathrm{C}^{*}$ & $\mathrm{Ag} 10 \mathrm{~B}$ & $\operatorname{Ag} 20 C^{*}$ & $\mathrm{Ag} 20 \mathrm{NiC}$ \\
\hline Current density, $\left[\mathrm{A} / \mathrm{dm}^{2}\right]$ & 15 & 15 & 15 & 10 & 20 & 20 \\
\hline Working voltage, $[\mathrm{V}]$ & $4.5 \ldots .5 .0$ & $4.5 \ldots .5 .0$ & $4.5 \ldots 5.0$ & $4.0 \ldots 4.5$ & $6.0 \ldots 6.5$ & $6.0 \ldots 6.5$ \\
\hline Deposition temperature $\left[{ }^{\circ} \mathrm{C}\right]$ & 24 & 24 & 24 & 23 & 26 & 26 \\
\hline Deposition rate, $[\mu \mathrm{m} / \mathrm{hr}]$ & 38 & 43 & 41 & 37 & 68 & 68 \\
\hline Thickness of the substrate, $[\mathrm{mm}]$ & 0.190 & 0.388 & 0.305 & 0.181 & 0.283 & 0.167 \\
\hline Thickness of the coating, $[\mu \mathrm{m}]$ & 2.8 & 5.4 & 4.6 & 11.0 & 13.0 & 13.0 \\
\hline Modulus of elasticity, [GPa] & $126 \pm 7$ & $139 \pm 17$ & $177 \pm 25$ & $158 \pm 27$ & $85 \pm 15$ & $102 \pm 41$ \\
\hline Mean residual stress & 196.5 & 221.4 & 185.8 & 114.6 & 145.1 & 142.9 \\
\hline by curvature method, $\left[\mathrm{N} / \mathrm{mm}^{2}\right]$ & 48.7 & 61.7 & 37.8 & 33.2 & 40.9 & 30.2 \\
\hline Relation, $\sigma_{0} / \sigma_{\mathrm{f}}$ & 4.03 & 3.59 & 4.92 & 3.45 & 3.55 & 4.73 \\
\hline Nanohardness, [GPa] & $4.42 \pm 0.50$ & $4.24 \pm 0.52$ & $4.61 \pm 0.22$ & $2.40 \pm 0.38$ & $3.19 \pm 0.14$ & $3.34 \pm 0.26$ \\
\hline $\begin{array}{l}\text { Maximum indentation depth } h_{\max } \text { at } \\
\text { load } 10 \mathrm{mN},[\mathrm{nm}]\end{array}$ & 307 & 324 & 315 & - & 414 & 376 \\
\hline $\begin{array}{l}\text { Contact depth } h_{\mathrm{c}} \text { at load of } 10 \mathrm{mN} \text {, } \\
\text { [nm] }\end{array}$ & 306 & 322 & 312 & - & 323 & 343 \\
\hline $\begin{array}{l}\text { Mean residual stress by nano- } \\
\text { indentation technique } \sigma_{\mathrm{r}},\left[\mathrm{N} / \mathrm{mm}^{2}\right]\end{array}$ & 41 & 65 & 51 & - & 68 & 103 \\
\hline
\end{tabular}

Additional code signs: B, C - brass and copper substrate, respectively, ${ }^{*}$ - thicker substrate, $\mathrm{Ni}$ $0.4 \mu \mathrm{m}$ nickel underlayer

Residual stresses and hardness of gold- and silver-plated layers is an extremely important durability related issue when slip rings of generators are coated.

The typical surface morphology and the cross section of the gold and silver coatings are presented (Fig. 7).

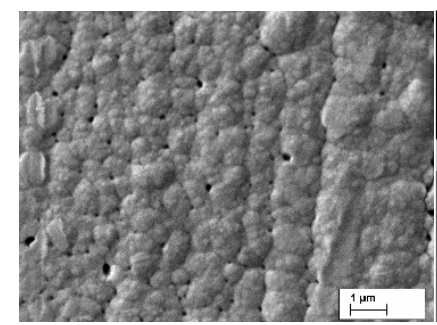

a
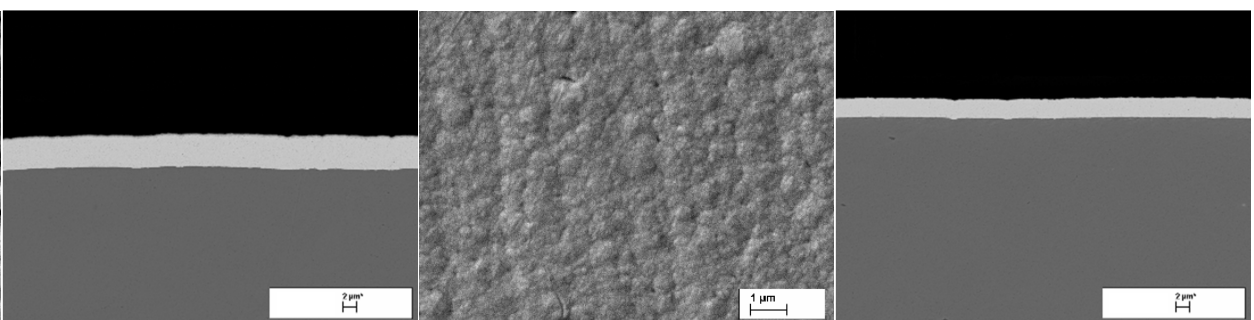

b
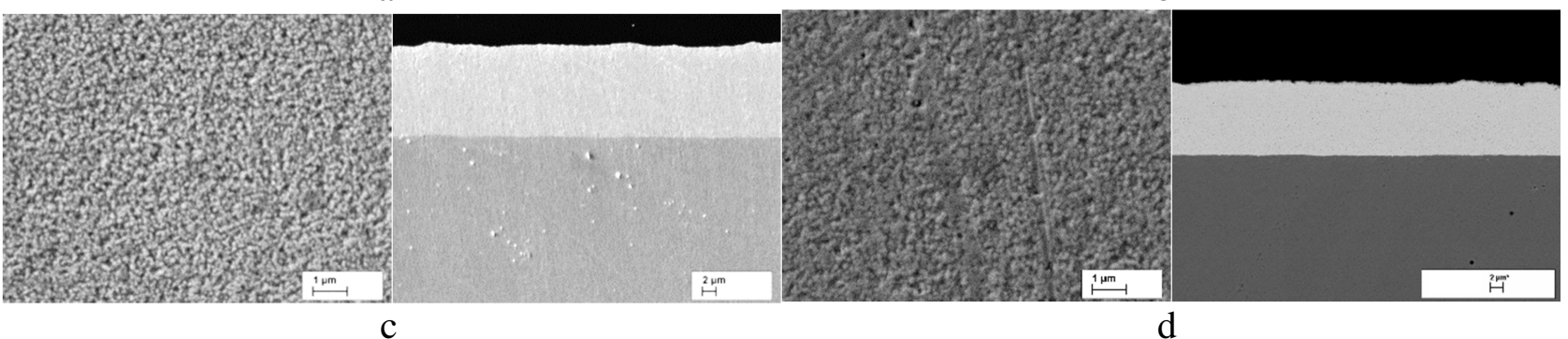

Fig. 7. Morphology and cross sections of the gold and silver coatings: a) Au15C*, b) Au15B, c) Ag20NiC, d) Ag10B

Brush-plated coatings have a fine crystalline nanostructure which is caused by the high deposit current. The coatings have carbon impurities originated from the graphite anode, which can have an effect on the mechanical properties of the coating material, especially in the case of gold coating Au15C*. When coating thickness increases then also the roughness of coated surface increases and therefore finishing is needed for obtaining mirror surface.

In the future more experimental effort, aimed to evaluate the microstructure of coatings during relaxation of residual stresses, is needed. 


\section{Summary}

Residual stresses decreased markedly, 3.5 to 5.0 times in the investigated coatings, but relaxation was faster in the silver coatings. The values of residual stresses depended on current density but evidently not on the material or thickness of the substrate. Approximation of the calculated values of residual stresses, depending on relaxation time, with the use of the presented formula, was satisfactory.

The values of residual stresses obtained by the two different methods were comparable. The nanohardness of the gold coatings was significantly higher than that of the silver coatings. The measured values of the modulus of elasticity of the coating materials fluctuated to a great extent. Crystalline structure of the silver coating was somewhat finer.

This analysis was limited to the data obtained from the experiments described above.

\section{Acknowledgements}

This study was supported by the Estonian Science Foundation (SF0140091s08). The authors would like to thank Valdek Mikli, PhD for helping in SEM measurements.

\section{References}

[1] H. Lille, J. Kõo, A. Ryabchikov, R. Reitsnik, R. Veinthal, V. Mikli, F. Sergejev, Investigation of Residual Stresses and Some Elastic Properties of Brush-Plated Gold and Silver Coatings, Key Engineering Materials, Engineering Materials and Tribology 527 (2013) 125-130.

[2] H. Lille, J. Kõo, A. Ryabchikov, Measurement of Residual Stresses in Different Electrochemical Metallized Coatings, Proceedings of the Lithuanian Academy of Sciences. Materials Science (Medžiagotyra) 4 (2002) 417-420.

[3] H. Lille, J. Kõo, T. Pihl, Measurement of Residual Stresses in Brush-Plated Gold and Silver Coatings on Thin Cross-Cut Ring Substrate, Latvian Journal of Chemistry (Latvias Kimijas Žurnals) 1 (2008) 48-54.

[4] R. Weil, The origin of stresses in electrodeposits. Review of the Literature Dealing with Stress in Electrodeposited Metals. Part I. Plating 57 (12) (1970) 1231-1237.

[5] C. Klein, G. Cardinale, Young's Modulus and Poisson's Ratio of CVD Diamond, Pros SPIE 1759 (1992) 178-193.

[6] Micro and Nano Mechanical Testing of Materials and Devices. Ed. Fuqian Yang, James C.M. Li. Springer, 2008, p. 394.

[7] X. Chen, J. Yan, A. M. Karlsson, On the determination of residual stress and mechanical properties by indentation. Materials Science and Engineering A 416 (2006) 139-149.

[8] J. Jang, Estimation of residual stress by instrumented indentation: A review. Journal of Ceramic Processing Research. Vol. 10, No. 3 (2009) 391-400. 